\title{
Clonality in Invasive Alien Macrophytes in Kashmir Himalaya: A Stage Based Approach
}

\section{GOWHER WANI ( $\nabla$ gowhar.wani88@gmail.com )}

Department of Science and Technology, Ministry of Science and Technology https://orcid.org/0000-0002-2276-9633

Asgar Khan

University of Kashmir

Afshana Afshana

University of Kashmir

Mudasir Dar

University of Kashmir

Zafar Ahmad Reshi

University of Kashmir

Amjad Husaini

Sher-E-Kashmir University of Agricultural Sciences and Technology Kashmir

Manzoor Ahmad Shah

University of Kashmir

\section{Research}

Keywords: Clonality, Clonal growth organs, CLO-PLA, Growth form, Kashmir Himalaya, PLADIAS, Plant invasion

Posted Date: February 4th, 2021

DOI: https://doi.org/10.21203/rs.3.rs-166440/v1

License: (c) (i) This work is licensed under a Creative Commons Attribution 4.0 International License. Read Full License

Version of Record: A version of this preprint was published at Aquatic Sciences on December 17th, 2021. See the published version at https://doi.org/10.1007/s00027-021-00843-2. 


\section{Abstract}

Background

The invasion of non-native species is a major cause of the global biodiversity loss and creates enormous economic costs. What determines alien invasive species dominance over native plant species is still little known, but there is an emerging pattern that many of the world's worst invasive plants are successful invaders due to the significant connection between their clonal traits and invasiveness. Freshwater ecosystems are relatively more prone to decline and extinction of species caused by biological invasion than terrestrial and marine ecosystems. In view of the lack of information about whether or not aquatic alien species at different stages of invasion exhibit any significant relation with clonality, the specific question addressed in this study was whether there is any relationship between clonality and invasiveness in aquatic macrophytes and how does it vary along different stages of invasion?

Results

While the link between clonality and species invasiveness has recently been recognized, whether and how clonality varies with different invasion-stages remains open questions. Hence, we tested the relationship between clonality and species invasiveness of Kashmir Himalayan aquatic macrophytes vis-à-vis its variability along different stages of invasion. The data on clonality, stage of invasion, and growth form was obtained through an extensive survey of literature and database like CLO-PLA (CLOnal PLAnts, version 3) and PLADIAS (Plant Diversity Analysis and Synthesis, 2014-2018) followed by evaluation of the clonal organs thorough intensive field surveys undertaken over a period of 3 years (2014-2017) in different aquatic habitats of the Kashmir valley. Our results showed that $84 \%$ of the studied species and almost $90 \%$ of the most invasive species (stage V sensu Colautti and Maclsaac 2004 ) are clonal. A strong positive correlation $(r=0.94 ; p<0.05)$ between clonality and invasiveness was observed, which further substantiates this association at a broad geographical scale representing the whole region. From the scatter matrix and Pearson's correlation matrix, clonality seems to have a strong positive correlation with fragments, rhizomes, runners, turions, tubers, and buds, thereby further affirming the strong nexus of clonality with species invasions.

\section{Conclusions}

Our results showed strong association of clonal architecture with not only the stages of invasion but also the distribution pattern of alien species in aquatic habitats, thereby indicating the pivotal contribution of clonality to invasiveness. Future studies directed at unraveling the reasons behind clonality need to be undertaken from the genomic perspective, in order to evolve better models for proper management of alien aquatic invasive species.

\section{Background}

The rapid spread of invasive alien plants, overrunning the habitats of native species, causes enormous economic and ecological damage [1, 2]. For instance, Myriophyllum spicatum (water milfoil), an aquatic macrophyte, in Lake Tahoe of Sierra Nevada (United States), caused a 1\% loss, which in monetary terms amounts to US\$500 000 annually [3, 4]. In Wular Lake, Asia's one of the largest freshwater lakes, Alligator weed (Alternanthera philoxerodies) forms dense floating patches that block light penetration to lower strata, create high biological oxygen demand and promote sedimentation and flooding [5]. The invasive alien species change ecosystem dynamics by effecting ecosystem structure and functioning, including reduction in native species diversity, modification of soil nutrient pools and fluxes, and alteration of ecosystem productivity [6-8]. Invasive species are thought to be successful in their introduced environments because they occupy novel or empty ecological niches, and/or they possess fitness differences that drive competitive dominance over resident communities [9]. Invasive plant species also impose new selective pressures on native species which may result in evolutionary changes in some native species, reducing competitive exclusion and allowing for coexistence with the invader [10]. The ecosystem of low resistance and below-par managed natural resources are found to be prone to change their species abundances and compositions due to increased invasions [11], which further deteriorates these ecosystems by forming monotonous mats on water surface thereby preventing the light penetration, decreasing dissolved oxygen and declining phytoplankton productivity. Though invasive plants have detrimental impact on the environment but sometimes they can act as remedy to the weak ecosystem and can have positive impact [12]. For example, a positive, hyperbolic relationship between invasive Gracilaria cover and abundance and richness of epifauna was found which revealed positive ecosystem multi functionality with invasion [13]. Similarly, non-native wetland plant species (Phragmites australis and Hydrilla verticillata) in North America, provide more suitable habitat for waterfowl, more biomass production and nitrogen retention than native wetland plant species [14]. In addition, freshwater ecosystems are relatively more prone to decline and extinction of species caused by biological invasion than terrestrial and marine ecosystems [15]. Being a rich provider of a wide-ranging variety of ecosystem services and goods, the freshwater biodiversity is progressively threatened by extensive resource exploitation, habitat degradation, water flow changes, pollution [16] but invasion of alien species appears to impact the ecosystem most severely $[17,18]$ thereby creating unfavorable conditions for the native species by strongly modifying local factors [19-22]. Moreover, many aquatic plants have a huge potential of quickly increasing their spatial distribution, thus making them characteristically invasive [23].

The mountainous region of Kashmir Himalaya harbors 3813 wetlands and water bodies [24], which have been studied for various aspects of biodiversity, environmental status in terms of hydrology [25], limnology [26], trophic structure [27], food chain structure [28], but the role of clonality in aquatic plant invasion has received very scanty attention [29]. A disproportionate fraction of aquatic plant species reproduce vegetatively mainly due to the possession of a wide range of clonal growth organs [30-33]. Competitive interactions occur between the invasive and native species, where the former generally outcompete the native species of the resident community, resulting in a successful invasion [34-37]. What determines alien invasive species dominance over native plant species is still little known, but there is an emerging pattern that many of the world's worst invasive plants are successful invaders due to the significant connection between their clonal traits and invasiveness. Aquatic plants display a remarkable range of reproductive strategies, including diverse sexual systems and means of clonal propagation [38]. There are conflicting views on whether or not certain reproductive adaptations are of special value to weedy species. variation in reproductive traits will influence the ability of populations to colonize and persist in different types of aquatic habitats and probably vast majority of weeds are self-compatible or possess strong powers of vegetative reproduction [39]. Baker feels that these characteristics are of importance in the long distance dispersal of weeds. Therefore, the question being asked here is whether clonal traits (clonal organs) associated with alien invasive clonal plants 
help them to dominate over native plants. Asexual reproduction in clonal plants provides several ecological benefits compared to sexual reproduction. These benefits include the ability of clones to acquire different resources from multiple sites through horizontal organs [40], store nutrients in below-ground clonal architecture for long term persistence in cold environments [41], increase the ability of clonal propagates to disperse to new environments, intraclonal resource sharing among ramets in response to resource heterogeneity [42], opportunities for physiological integration and spatial division of labor between ramets; and clonal integration can increase the fitness of performance-related clonal traits and thus can multiply rapidly and compete effectively over non-clonal plants $[43,44]$. Importantly, clonal reproduction provides a safe alternative to risky seed production and recruitment [45]. Consequently, clonal reproduction is thought to play an important role in population persistence and conservation in hostile environmental conditions [30], and a significantly higher proportion of clonal reproduction have been observed to occur in cold environmental conditions than in temperate environments [46, 47]. Asexual reproduction in clonal plants also provides several evolutionary benefits, including the gain of advantage by avoiding the costs associated with sexual reproduction and a means by which clonal species can be rapidly adapted after colonization to the new environments they face [48]. Clonal plants often persist for longer periods in habitats in which sexual reproduction is prevented, either because of the absence of mating partners, or where environmental conditions are not favorable for seed germination, seed set, or seedling establishment [48].

Clonal integration has been suggested to contribute to the global invasiveness of clonally growing plants from the results of a meta-analysis, in which the link between the degree of invasiveness and clonal integration of about 60 clonal plants were examined [49]. Alarge proportion of plant species are clonal [30, 50, 51], consisting of a network of cloned individuals connected by a large network of below-ground spacers mostly by rhizomes and stolons [52, 53]. In contrast to non-clonal plants, clonal plants haveadditional features in terms of number of ramets (root-shoot unit), branching pattern of clonal organs such as rhizomes, and stolon andthe length of the spacer between ramets [54-56]. The potential of alien species to invade new areas may be predicted from the influence of their native region [57] and similarityin the environmental factors between native and invaded regions favours the plant invasion. If the species has a large native geographical area, the possibility of transfer of its propagules increases to the region with a similar climate [58, 59]. The aquatic flora of Kashmir Himalaya was recently compiled and all the species were characterized on the basis of different invasion stages, in accordance with the $\mathrm{CM}$ model proposed by (Colautti and Maclsaac) [60]. The CM model describes seven stages (0, I, II, III, IVa, IVb, and V) which are reflective of the sequential series of steps involved in the process of biological invasions. The $\mathrm{CM}$ model has been successfully tested by some workers [59, 61], though more studies need to test the model for its robustness and widescale applicability to take it forward from its stage of scientific infancy.

In view of the lack of information about whether or not aquatic alien species at different stages of invasion exhibit any significant relation with clonality, the specific question addressed in this study was whether there is any relationship between clonality and invasiveness in aquatic macrophytes and how does it vary along different stages of invasion? We used 102 major invasive alien plant species found in the aquatic habitats of Kashmir Himalaya and representing different life forms, invasion stages, and clonal organs for this purpose.

\section{Materials And Methods}

\section{Study Area}

With a large biogeographic domain, the valley of Kashmir is situated in the north-western Himalayas [62]. The region comes under coordinates of (33 $22^{\prime}$ and

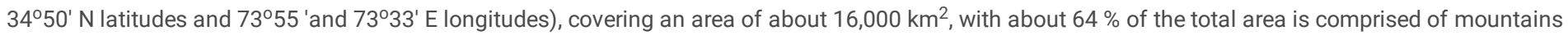
[63]. The valley is a deep elliptical bowl-shaped surrounded by a girdling chain of high mountain ranges, namely the Pir Panjal in the south and south-west, and the Zanskar, the Greater Himalayan range in the north and north-east.

Also, the valley of Kashmir has a network of numerous glaciated streams, lakes, springs, rivers as well as alpine, sub-alpine, and freshwater ecosystems along an altitudinal gradient, mainly due to its unique edaphic characteristics, eco-climatic conditions, and geographical location, together with its undulating topography and lofty snowcapped mountains and hills.

\section{Data collection}

We targeted the aquatic flora of Kashmir Himalaya with special reference to lakes and wetlands for the present study. In the beginning, information about the occurrence, distributional range, invasiveness, clonality, origin, growth form, life form, and stages of the invasion were obtained through extensive screening of available literature such as, specimens of the targeted flora that was stored in the Kashmir University Herbarium (KASH), published research articles, weed floras, etc. The most valuable source of information about the presence of aquatic invasive species among different habitats were perused [25, 64-75].

Pursuant to useful information gained through the study of previous literature, we followed up with thorough field surveys undertaken for a period of 3 years (2014-2017), in different aquatic habitats of the Kashmir valley. Species were grouped in invasion stages based on the extent of spatial spread in the Kashmir Himalayan region, measured in terms of the frequency percentage across sites using standard quadrat sizes of $0.5,1$, and $5 \mathrm{~m}^{2}$ for free-floating submerged, and emergent macrophytes, respectively, in the framework of the CM model.

The field data were collected during seasonal surveys inthe target water bodies. During the survey, a total of 125 species were recorded from 9 lakes, 5 wetlands, 7 streams, and 2 rivers. Out of them, 102 species were included in the present study, while the remaining 23 species were excluded because of insufficient information (Appendix 1). A total of $2300\left(1 \mathrm{~m}^{2}\right)$ quadrats were laid randomly (100 in each water body) across different zones (littoral, marsh, open waters) to take into account maximum macrophytic diversity for the present analysis.

All the species were uprooted to ascertain whether it is clonal or non-clonal. All the clonal species were evaluated for their clonal organs (Appendix 1 ). We evaluated the clonal organs after the flowering and fruiting stage, and at the end of a season which was the best time for evaluation because some of the clonal traits develop at the later stages. For clonal organ evaluation, two to ten individual plants of each species were excavated with below-ground organs. 
For conformity whether we are in correct identification of the clonal growth organs and life form for each species from the wetland species pool,we used the CLO-PLA 3 (CLOnal PLAnts, version 3) of the CLOPLA database (http://clopla.butbn.cas.cz/). This online data-base of clonal growth of plants, which contains clonal traits and vegetative regeneration of about 186,157 records of 2,923 species for the European temperate flora. This data-base is freely available and can serve as a guide for clonal trait sampling in different parts of the globe, together with specific detailed information on how to use it and the nature of clonal traits [50, 76] and PLADIAS (Plant Diversity Analysis and Synthesis, 2014-2018) of the Pladias-database of the Czech Flora and Vegetation (www.pladias.cz) of clonal growth in plants. It includes more than 13 million records of almost 5 thousand taxa (species, subspecies, varieties and hybrids), which came from seven regional projects, five large national databases and records collected within the PLADIAS project. The Pladiasdatabasecovers largest set of data on vascular plants of the Czech Republic [77]. The present study covered almost all the major aquatic habitats, including ninelakes (Anchar, Dal, Hokarsar, Wular, Mansbal, Ahansar, Narangbagh, Nilnag, and Waskar), five wetlands (Shallabugh, Tulmula, Malangpora, and Kranchu), seven streams (Achabal, Bal-Kol, Irrigation canal and spring stream of Sundoo, Nambal rivulet, Nagrad stream, Aarpath rivulet, and Spring stream) and two rivers (Jehlum and Sindh) and their tributaries (Table 1).

River Jehlum is the main river of the Kashmir valley. The major tributaries of the Jehlum river includes; Sind (Ganderbal/ Srinagar), Lidder (Anantnag), Rambiara (Pulwama/ Kulgam) and Pohru (Kupwara).The minor tributaries of the Jehlum includes, ArapatKol, Vishav, Sandran, Bringi, and Romushali (Anantnag, Kulgam); Arapal (Pulwama); Harwan (Srinagar); Rambiara (Shopian); Vij-Dakil, Erin, Madumati, and Ningal (Bandipora, Bramulla) and SukhnagFirozepora, Dudhganga- Shaliganga, (Budgam, Baramulla). In addition to these, there are many ponds, marshes and irrigation channels which support various species of aquatic plants.

Data on geographic origins, degree of invasiveness, growth form, life form and stage of invasion of 102 invasive alien plant species in Kashmir Himalaya were obtained from personal field surveys and other published sources [73, 75] (Appendix I and Table 8) and the majority $(72.89 \%)$ of invasive alien species are of European origin (Fig. 4).

\section{Data analysis}

Data analysis was done in R Studio (version 1.2.1335; $\mathrm{R}$ version 3.6.2). The association of clonality and invasion stage was discerned by performing the simple Pearson's correlation. Additionally, we attempted to consolidate the individual contribution of different clonal growth organs towards clonality and how closely associated the latter is to different life forms by performing principal component analysis (PCA) using the ggbiplot package in R studio [78]. By doing this we transformed a large number of possibly correlated variables into an even smaller number of uncorrelated variables called principal components.

\section{Results}

\section{Clonal growth organs, invasion stage and growth form categorization.}

All the clonal species belonging to the variouswater bodies were categorized into 12 different types based on the type of clonal growth organs, distributed among five invasion stages (Table 2) and four different life forms (Table 3). Most of the species were found to have more than one type of clonal growth organ and were hence represented in different clonal growth organ categories. Clonal plants constituted more than three quarters (84.31\%) of the investigated 102 alien aquatic species, with hydrophytes representing $48.8 \%$ of all the clonal species, followed by Hemicryptophytes, Geophytes, and Therophytes with their respective shares to clonality as $26.74 \%, 16.26 \%$, and $8.14 \%$, respectively. Hemi cryptophytes are plants whose clonal organs (e.g. perennating buds) are at ground level, the aerial shoots dying down at the onset of unfavorable conditions. Geophytes are perennial plants that possess and propagates by means of buds, bulbs, tubers, corms, or rhizomes below the soil surface. Therophytes are plants that pass the unfavorable season only through the seeds but proliferate through clonal organs like the ramets or clonal offshoots in the growing season.

\section{Clonality and clonal growth organs vis-à-vis stages of invasion}

With the increasing stage of invasion, there is a progressive increase in the abundance of clonal plants.Out of 25 plant species at invasion stage $\mathrm{V}$, $91.17 \%$ turned out to be clonal. The stage $\mathrm{V}$ species (most invasive plants) therefore, represents a maximum fraction of clonal plants (Table 4). A strong positive correlation ( $P<0.05 ; r=0.94$ based on 102 plant species) between the invasion stage and clonality was observed using Pearson's correlation coefficient.

\section{Identification of possible factors (clonal growth organs) affecting clonality}

Clonality in plant species arises due to a number of clonal growth organs, and some plant species bear more than one type of clonal organ. Correlations (Table 5 and Fig. 1) were computed to evaluate the correlations among different variables. Pink colored boxes in the scatter matrix show high and significant correlation among the variables; the blue boxes show moderate correlation while the yellow boxes doesn't indicate any sort of correlation. From the scatter matrix and Pearson's correlation matrix, clonality seems to have a strong positive correlation with fragments, rhizome, runner, turion, tubers, and buds. Given the availability of a large number of interrelated variables (clonal growth organs), principal component analysis, with intentions to reduce the dimensionality of the variables, was performed. This transformed the whole data into a new set of variables, the principal components which are orthogonal (non-correlated) and arranged in decreasing order of variance.

The correlation of clonality with clonal growth organs (CGS) was consolidatedby multivariate data analysis through principal component analysis (PCA), as shown in Table 6 \& Figure. 2. The eigen values that arose out of the principal component analysis shows that the first two principal components accounted for $87.2 \%$ of the total variance (PC1 52.3\%; PC2 34.9\%). The percentage of the explained variances surges up to $95.8 \%$ when the third principal component was taken into consideration (Table 6). In view of the large number (12) of variables studied, PC1 and PC2 were taken for further analysis. 
The scores of five invasion stages and the loadings of 12 clonal growth organ variables are shown in Fig. 2. In the PC1, which explains $52.3 \%$ of the total variance, there are strong positive loadings for rhizome, turion, runner, clonality, buds, fragments, and tubers. The positive contribution of these variables, particularly fragments, buds, and tubers, to this component indicates their significant contribution towards clonalityof species resident at the invasion stage $\mathrm{V}$ (Table 6, Fig 2). Again in the PC1, stolons, pleiocorms, corms and bulbs with moderate loadings seem to contribute considerably to the clonality of species resident at invasion stage III. Similarly, PC2, which makes out $34.9 \%$ of the total variability in the data,depicts strong positive loadings for ramets, fragments, buds, tubers, turions and tillers. Among all these clonal growth organs, though with moderate loadings tillers are found to contribute significantly to the clonality of species placed at invasion stages IVa, IVb, and II. (Table 6, Fig 2).

\section{Clonality, life forms and clonal growth organs (CGO's)}

The alien aquatic plant species distributed among four different life form categories having 12 types of clonal growth organs with some species showing more than one type of clonal organs. PCA was done to analyze the association between clonality, life form, and different types of clonal growth organs. Table 7 and Fig. 3 provides the outcome of the PCA. $86.6 \%$ of the total variance in the data set is attributed to the first two principal components with respective shares of $65.6 \%$ and $21 \%$. With the inclusion of the third principal component (PC3), $100 \%$ of the variance in the data set gets explained (Table 7 ).

The PC 1 , which accounts for $65.6 \%$ of the total variance in the data set shows strong positive loadings for ramets, corms, tillers, bulbs, and pleiocorms. The PC2, which adds $21 \%$ to the total variance exhibited strong positive loadings for tubers, turions, and fragments. Thesame directionality of these strongly contributing factors and clonality alongside other low contributing factors like stolons, rhizome, runner, and buds points to the close association of clonality and all these factors (Fig. 3 Table 7). A keen look at Fig. 3 also indicates that a major share of fragments, turions, runners, rhizomes, stolons and buds contributes strongly to the clonality of hydrophytes. Tubers and ramets as seen in the biplot seem to contribute to the clonality of geophytes. Besides imparting to the clonality of geophytes ramets also appear to add to the clonality of therophytes in association withtillers, corms, pleiocorms, and bulbs. Finally, pleiocorms and bulbs besides sharing to the clonality of therophytes, also add to the clonality of hemi kryptophytes.

\section{Discussion}

Arbitrarily linking species invasiveness to clonality without figuring out the principal components seems rather unrealistic and has greatly redacted the highly useful information on invasive species. Since, in our case, $84 \%$ of the studied species and almost $90 \%$ of the most invasive species (stage $V$ ) turned out clonal, it is quite rational to discuss future implications of the clonality on species invasions and range shifts. A strong positive correlation ( $p<0.05)$ found between clonality and invasiveness substantiates this association at a reasonably wide regional scale, representing the entire Kashmir Himalayan region. The distinction of clonal growth forms and significant positive correlation between clonality and different clonal growth organs (fragments, rhizome, runner, turion, tubers, and buds), further affirms the strong nexus of clonality with species invasions. These results, though in concordance with some recent studies [73, 79], are credited to unveil new grounds behind the successful spread of clonal species in wetlands. We ascribed this mainly to the novel analytical approach and a more comprehensive study region than the previous studies. Earlier, Reichard et al. [80] reported aclose correlation between the invasiveness and clonality of American wetland plants. Since the association of clonality and invasivenessis thought to be species-specific [79], studies like those of Pyšek et al. [81], advocating production of invasive hybrid genotypes by rare sexual reproduction andtheir clonal growth mediated fixation benefits over native species [79], are highly recommended. Our work stands distinct from those done in the past $[79,80,82,83]$ mainly because of the inclusion of more study sites and dimensionality reduction in the data set, affording least loss of original information. Plant invasion has become a significant threat to biodiversity for environments and economies, both globally and locally $[2,79,84]$. There are a considerable number of invasive plantspecies that are capable of vigorous clonal propagation, andtheir invasiveness may be related to clonal integration [79]. Many studies have shownthat clonal integration can enhance plant invasion successin alien plants [80,85-88]. Other pieces of evidence in favour of the clonality-invasiveness correlation which strongly corroborates our findings are that of $[89,90]$, suggesting that most serious invaders are better adapted to environmental conditions [91-93]and displace natives through intense competition. Although varied and many, the prime and worthwhile advantages of having CGO's in heterogeneous habitats include; reduction of genetic risk [94, 95], efficient sharing of resources within a clone [96], foraging behavior [91] and proper apportionment of labour [42]. In comparison to terrestrial habitats, aquatic systems have been found to accommodate a greater fraction of invasive species with a disproportionate representation of clonal [75]. High vegetative multiplication concurrent to efficient nutrient use and vigorous growth [97] grants competitive advantage and invasive potential to exotic invaders in nonnative ranges. Since a major fraction of clonal species were reported as polyploids $[75,98]$ and the most severe invasive plants, both aquatic and terrestrial ecosystems, have polyploid genetic makeup [75, 99], it is worthwhile to underscore the importance of genetics and Species' ploidy status in future invasion studies. Recently, Wani et al. [75] documented the ploidy status of 118 alien aquatic species distributed to various aquatic habitats of KashmirHimalaya at various stages of invasion,observed that both polyploidy and invasiveness increases with progressing stages of invasion (stage I to stage V), thus polyploidy is one of the determinant factor for plant invasiveness. The comparatively greater percentage of polyploid species at these progressive stages are possibly because of their increased resistance to pests, pathogen, increased resistance to nutrient stress, genetic drift, altered physiology and comparatively wider range of ecological tolerance [100-105]. These findings clearly indicate that both clonality and polyploidy have strong association with species invasiveness. As both clonality and polyploidy increases when increasing the stages of invasion.

In addition, clonal growth organs enable plant species to exploit vacant resource-abundant patches, and the interconnected network of ramets in some cases are believed to mediate in the transfer of information and resources, besides their storage $[49,76,106,107]$. Enhanced anchorage and formation of the dense canopy by clonal macrophytes in wetlands also reduces the effects of different aero- and hydrodynamic forces [85, 108]. Furthermore, lateral expansion of clonal plants in stressful conditions of running water successfully economize resource utilization at the cost of less efficient non-clonal plants [109]. Diversity in the clonal architecture of plants may enhance their performance under varied environmental conditions [110-114], allowing these species to invade a wide range of habitats. Notwithstanding the multitude of benefits by being clonal, the associated dispersal limitations slow down the invasion pace [115], which in most cases is offset by having both sexual and asexual reproductive means with plastic allocation to each reproductive strategy [116]. Uniparental reproduction (e.g. asexual reproduction) during colonization can provide reproductive pledge when mating partners are sporadic [117]. However, asexual 
reproduction hampers opportunities for genetic admixture and recombination, which can expand founder effects and upturn the probability of stochastic processes prompting patterns of genetic polymorphism $[118,119]$. Furthermore, the prolific clonal dispersal of vegetative propagules can promote "mate finding," mostly in aquatic plants [48]. In species in which clonal propagation preponderates, mutations decreasing fertility may lead to sexual dysfunction and even the loss of sex. Recent evidence suggests that somatic mutations can play an important role in prompting fitness in clonal plants and may also help to determine the genetic variability in sterile clonal populations [120,121]. Clonal aquatic plants often persist for longer periods in wetland habitats in which sexual reproduction is prevented, either because of the absence of mating partners, lack of pollinators, or where ecological conditions are unfavorable for seed germination, seed set, or seedling establishment [48]. Long-distance dispersal of only one mating type to a region, especially in invasive species, may disable sexual systems, resulting in sterility [122]. Asexual reproduction in clonal plants also provides several evolutionary benefits, including the gain of advantage by avoiding the costs associated with sexual reproduction and a means by which clonal species can be rapidly adapted after colonization to the new environments they face [48].

Higher phenotypic plasticity and a wider range of clonal growth organs in aquatic plants in the form of corms, rhizomes tubers, and turions [30, 38, 123] provide avenues for understanding the evolutionary and adaptive significance of variable resource allocation to growth and reproduction along moisture gradients. Furthermore, raising the life time reproductive success and guaranteeing the future population establishment prospectus in aquatic plants via persistent genets requires some trade-offs particularly priority of asexual over sexual reproduction [123]. Many reports suggest that clonal plants allocate more resources to vegetative than sexual reproduction under subdued light conditions in water to increase their future persistence [124]. There are also concrete evidences suggesting clonally propagated plants to be more successful in aquatic habitats which face frequent ecosystem disturbances and follow up recoveries $[123,125]$

\section{Conclusion}

Our results showed strong association of clonal architecture with not only the stages of invasion but also the distribution pattern of alien species in aquatic habitats, thereby indicating the pivotal contribution of clonality to invasiveness. Future studies directed at unraveling the mechanistic reasons behind clonality should include genomics of the concerning species in the models in an, evolutionary context to better inform the management models for aquatic plant invaders.

\section{Abbreviations}

CLO-PLA: CLOnal PLAnts

PLADIAS: Plant Diversity Analysis and Synthesis

CM : Colautti and Maclsaac

CGO's : clonal growth organs

PCA: Principal component analysis

\section{Declarations}

\section{Acknowledgements}

The financial support by DST-SERB, Govt. of India under the National Post-Doctoral Fellowship (N-PDF) (PDF/20l8/001689) to GAW is acknowledged.

\section{Authors' contributions}

GAW, MAS and ZAR conceived the idea and designed the study. GAW and MAK collected the data across the Kashmir Himalayan aquatic habitates and wrote the present manuscript. MAD and Afshana contributed to statistical analysis and writing of the manuscript. MAS, ZAR and AMH contributed to the writing of the present manuscript. Together, the authors revised and corrected the manuscript versions. All authors have read and agreed to the published version of the manuscript.

\section{Funding}

This study was funded by DST-SERB, Govt. of India under the National Post-Doctoral Fellowship (N-PDF).

\section{Availability of data and materials}

The datasets supporting the results and conclusions of this article are included as (Appendix) supplementary information.

\section{Ethics approval and consent to participate}

Not applicable.

\section{Consent for publication}

Not applicable. 


\section{Competing interests}

The authors declare that they have no competing interests.

\section{References}

1. Schmitz DC, Simberloff D. Biological invasions: a growing threat. Issues Sci Technol.1997;13(4):33-40.

2. Mack RN, Simberloff D, Mark Lonsdale W, Evans H, Clout M, Bazzaz FA. Biotic invasions: causes, epidemiology, global consequences, and control. Ecol Appl. 2000;10(3):689-710.

3. Eiswerth ME, Darden TD, Johnson WS, Agapoff J, Harris TR. Input-output modeling, outdoor recreation, and the economic impacts of weeds. Weed Sci. 2005:130-7.

4. Pejchar L, Mooney HA. Invasive species, ecosystem services and human well-being. Trends Ecol Evol. 2009;24(9):497-504.

5. Keller RP, Masoodi A, Shackleton RT. The impact of invasive aquatic plants on ecosystem services and human well-being in Wular Lake, India. Reg Environ Change. 2018;18(3):847-57.

6. Liao C, Peng R, Luo Y, Zhou X, Wu X, Fang C, et al. Altered ecosystem carbon and nitrogen cycles by plant invasion: a meta-analysis. New phytol. 2008;177(3):706-14.

7. Pyšek P, Jarošík V, Hulme PE, Pergl J, Hejda M, Schaffner U, et al. A global assessment of invasive plant impacts on resident species, communities and ecosystems: the interaction of impact measures, invading species' traits and environment. Glob Change Biol. 2012;18(5):1725-37.

8. Barney JN, Tekiela DR, Barrios-Garcia MN, Dimarco RD, Hufbauer RA, Leipzig-Scott P, et al. Global Invader Impact Network (GIIN): toward standardized evaluation of the ecological impacts of invasive plants. Ecol evol. 2015;5(14):2878-89.

9. MacDougall AS, Gilbert B, Levine JM. Plant invasions and the niche. J Ecol. 2009;97(4):609-15.

10. Zenni RD, Dickie IA, Wingfield MJ, Hirsch H, Crous CJ, Meyerson LA, et al. Evolutionary dynamics of tree invasions: complementing the unified framework for biological invasions. AoB Plants. 2017;9(1).

11. McNeely JA. The great reshuffling: human dimensions of invasive alien species: IUCN; 2001.

12. Goodenough A. Are the ecological impacts of alien species misrepresented? A review of the "native good, alien bad" philosophy. Community Ecol. 2010;11(1):13-21.

13. Ramus AP, Silliman BR, Thomsen MS, Long ZT. An invasive foundation species enhances multifunctionality in a coastal ecosystem. Proceedings of the National Academy of Sciences. 2017;114(32):8580-5.

14. Hershner $\mathrm{C}$, Havens KJ. Managing invasive aquatic plants in a changing system: strategic consideration of ecosystem services. Conserv Biol. 2008;22(3):544-50.

15. Johnson PT, Olden JD, Vander Zanden MJ. Dam invaders: impoundments facilitate biological invasions into freshwaters. Front Ecol Environ. 2008;6(7):357-63.

16. Dudgeon D, Arthington AH, Gessner MO, Kawabata Z-I, Knowler DJ, Lévêque C, et al. Freshwater biodiversity: importance, threats, status and conservation challenges. Biol Rev. 2006;81(2):163-82.

17. Zedler JB, Kercher SJCrips. Causes and consequences of invasive plants in wetlands: opportunities, opportunists, and outcomes. Crit Rev Plant Sci. 2004;23(5):431-52.

18. Olden JDJJoB. Biotic homogenization: a new research agenda for conservation biogeography. J Biogeogr. 2006;33(12):2027-39.

19. Urban RA, Titus JE, Zhu WX. An invasive macrophyte alters sediment chemistry due to suppression of a native isoetid. Oecologia. 2006;148(3):455-63.

20. Pierobon E, Bolpagni R, Bartoli M, Viaroli PJ. Net primary production and seasonal $\mathrm{CO} 2$ and $\mathrm{CH} 4$ fluxes in a Trapa natans L. meadow. J Limnol. 2010;69(2):225-34.

21. Andersen MR, Kragh T, Sand-Jensen K. Extreme diel dissolved oxygen and carbon cycles in shallow vegetated lakes. Proc Biol Sci. 2017;284(1862):20171427.1

22. Vilas MP, Marti CL, Adams MP, Oldham CE, Hipsey MR. Invasive macrophytes control the spatial and temporal patterns of temperature and dissolved oxygen in a shallow lake: a proposed feedback mechanism of macrophyte loss. Front Plant Sci. 2017;8:2097.

23. Richardson DM, Pyšek P, Rejmánek M, Barbour MG, Panetta FD, West CJ. Naturalizationand invasion of alien plants: concepts and definitions. Divers Distrib. 2000;6(2):93-107.

24. Romshoo SA, Sumira J. Department of Geology, Geophysics UoK, Srinagar, India, 123p. Geospatial tools for watershed characterization of the Dudhganga catchment, Jhelum basin. 2010.

25. Khan MA, Shah MA, Mir SS, Bashir S. The environmental status of a Kashmir Himalayan wetland game reserve: Aquatic plant communities and ecorestoration measures. Lakes \& Reservoirs: Research \& Management. 2004;9(2):125-32.

26. Zutshi DP, Subla BA, Khan MA, Wanganeo A. Comparative limnology of nine lakes of Jammu and Kashmir Himalayas. Hydrobiologia. 1980;72(1-2):10112.

27. Pandit AK, Kaul V. Management. Trophic structure of some typical wetlands. Welands: Ecol Manag.1982;2:55-82.

28. Pandit AK. University of Kashmir, Srinagar. Biotic factor and food chain structure in some typical wetlands of Kashmir. Unpublished Ph. D. thesis, University of Kashmir, Srinagar, 190006.1980. 
29. Bashir Shah A, Reshi ZA, Shah MAJJovs. Clonal trait diversity in relation to invasiveness of alien macrophytes in two H imalayan R amsar sites. J Veg Sci. 2014;25(3):839-47.

30. Grace JB. The adaptive significance of clonal reproduction in angiosperms: an aquatic perspective. Aquat Bot. 1993;44(2-3):159-80.

31. Boedeltje G, Bakker JP, Ten Brinke A, Van Groenendael JM, Soesbergen M. Dispersal phenology of hydrochorous plants in relation to discharge, seed release time and buoyancy of seeds: the flood pulse concept supported. J Ecol. 2004;92(5):786-96.

32. Combroux IC, Bornette G. Propagule banks and regenerative strategies of aquatic plants. J Veg Sci. 2004;15(1):13-20.

33. Dorken ME, Barrett SC. Phenotypic plasticity of vegetative and reproductive traits in monoecious and dioecious populations of Sagittaria latifolia (Alismataceae): a clonal aquatic plant. J Ecol. 2004;92(1):32-44.

34. Funk JL, Vitousek PM. Resource-use efficiency and plant invasion in low-resource systems. Nature. 2007;446(7139):1079-81.

35. Davidson AM, Jennions M, Nicotra AB. Do invasive species show higher phenotypic plasticity than native species and, if so, is it adaptive? A metaanalysis. Ecol Lett. 2011;14(4):419-31.

36. Pearse IS, Altermatt F. Predicting novel trophic interactions in a non-native world. Ecol Lett. 2013;16(8):1088-94.

37. Kuebbing SE, Nuñez MA. Invasive non-native plants have a greater effect on neighbouring natives than other non-natives. Nat Plants. 2016;2(10):1-7.

38. Barrett SC, Eckert CG, Husband BC. Evolutionary processes in aquatic plant populations. Aquat Bot.1993;44(2-3):105-45.

39. Baker HG. Self-compatibility and establishment after'long-distance'dispersal. Evolution. 1955;9(3):347-9.

40. Evans JP, Cain ML. A spatially explicit test of foraging behavior in a clonal plant. Ecology. 1995;76(4):1147-55.

41. Venn SE, Morgan JW. Diversity. Patterns in alpine seedling emergence and establishment across a stress gradient of mountain summits in south-eastern Australia. Plant Ecol Divers. 2009;2(1):5-16.

42. Alpert P. Division of labour in clonal plants. The ecology and evolution of clonal plants. 1997:137-54.

43. Van Groenendael J, Klimeš L, Klimešová J, Hendriks R. Comparative ecology of clonal plants. Philosophical Transactions of the Royal Society of London. Series B: Biological sciences. 1996;351(1345):1331-9.

44. de Kroon H, van der Zalm E, van Rheenen JW, van Dijk A, Kreulen R. The interaction between water and nitrogen translocation in a rhizomatous sedge (Carex flacca). Oecologia. 1998;116(1-2):38-49.

45. Callaghan T, Emanuelsson U. Population structure and processes of tundra plants and vegetation. The population structure of vegetation: Springer; 1985. p. 399-439.

46. Klimeš L, Klimešová J, Hendriks R, van Groenendalel J. Clonal plant architecture: a comparative analysis of form and function. In: de Kroon H. and van Groenendael J. (eds), The ecology and Evolution of Clonal Plants. Backhuys Publishers, Leiden. 1997;1-30

47. Stamati K, Hollingsworth P, Russell JJPS, Evolution. Patterns of clonal diversity in three species of sub-arctic willow (Salix lanata, Salix lapponum and Salix herbacea). PI Syst Evol. 2007;269(1-2):75-88.

48. Barrett SC. Foundations of invasion genetics: the Baker and Stebbins legacy. Mol Ecol. 2015;24(9):1927-41.

49. Song YB, Yu FH, Keser LH, Dawson W, Fischer M, Dong M, et al. United we stand, divided we fall: a meta-analysis of experiments on clonal integration and its relationship to invasiveness. Oecologia. 2013;171(2):317-27.

50. Klimeš L, Klimešová J. CLO-PLA2-a database of clonal plants in central Europe. Plant Ecol. 1999;141(1-2):9-19.

51. Sosnová M, van Diggelen R, Macek P, Klimešová J. Distribution of clonal growth traits among wetland habitats. J Aquat Bot. 2011;95(2):88-93.

52. Sosnova M, van Diggelen R, Klimešova J. Distribution of clonal growth forms in wetlands. J Aquat Bot. 2010;92(1):33-9.

53. Xu L, Yu F-H, van Drunen E, Schieving F, Dong M, Anten NP. Trampling, defoliation and physiological integration affect growth, morphological and mechanical properties of a root-suckering clonal tree. Ann Bot. 2012;109(5):1001-8.

54. Callaghan T, Svensson B, Bowman H, Lindley D, Carlsson B. Models of clonal plant growth based on population dynamics and architecture. Oikos. 1990:257-69.

55. Huber H, Lukács S, Watson MA. Spatial structure of stoloniferous herbs: an interplay between structural blue-print, ontogeny and phenotypic plasticity. Plant Ecol. 1999;141(1-2):107-15.

56. Ikegami M, Whigham DF, Werger MJ. Responses of rhizome length and ramet production to resource availability in the clonal sedge Scirpus olneyi A. Gray. Plant Ecol. 2007;189(2):247-59.

57. Reichard S. The search for patterns that enable prediction of invasion. In 'Weed risk assessment'.(Eds RH Groves, FD Panetta, JG Virtue) pp. $10-19$. CSIRO Publishing: Melbourne; 2001

58. Mihulka S, Pyšek PJ. Invasion history of Oenothera congeners in Europe: a comparative study of spreading rates in the last 200 years. J Biogeogr. 2001;28(5):597-609.

59. Shah MA, Reshi ZA, Lavoie CJ. Predicting plant invasiveness from native range size: clues from the Kashmir Himalaya. J Plant Ecol. 2012;5(2):167-73.

60. Colautti RI, Maclsaac HJ. A neutral terminology to define 'invasive'species. Divers Distrib. 2004;10(2):135-41.

61. Lawes RA, Murphy HT, Grice AC. Comparing agglomerative clustering and three weed classification frameworks to assess the invasiveness of alien species across spatial scales. Divers Distrib.2006;12(6):633-44.

62. Rodgers RCW, Panwar HS. Status report on snow leopard in India. Proc fifth international snow leopard symposium International Snow Leopard Trust, Seattle; 1988.

63. Ganaie SA, Bhat MS, Kuchay NA, Parry J. Delineation of micro agro-climatic zones of jammu and kashmir. Int J Agricult Stat Sci 2014;10(1):219-25.I 
64. Kaul V, Zutshi D, Vass KK. Aquatic weeds in Kashmir. Aquatic weeds in South East Asia Proceedings of regional seminar on noxious aquatic vegetation, New Delhi; 1976; 79-83.

65. Zutshi D. Associations of macrophytic vegetation in Kashmir lakes. Vegetation. 1975;30(1):61-6.

66. Kak A, Javeid GJ. Galium palustre L. and Eleocharis acicularis Roem et Schult.-two new plant records for India. J Bombay Nat Hist Soc. 1976;74:208-9.

67. Naqshi AR. Alternanthera caracasana Kunth.(Amaranthaceae) from Indian subcontinent. J Econ Taxon.1981;2:249-50.

68. Reshi Z. Ecology and taxonomy of weeds of District Anantnag, Kashmir Himalaya: M. Phil Dissertation, Department of Botany, University of Kashmir, Srinagar. 1984.

69. Kak AM. Family Alismataceae in the Kashmir Himalayas. J Bombay Nat Hist Soc. 1984;81:506-508.

70. Kaul MK. Weed flora of Kashmir valley: Scientific publishers; 2019.

71. Koul K, Naqshi AJ. Nymphaeaceae of Jammu and Kashmir. J Bombay Nat Hist. Soc.1988;85:454-5.

72. Kak AM. Aquatic and wetland vegetation of Kashmir Himalaya. J Econ Taxon Bot. 1990;14(1):1-14

73. Shah MA, Reshi ZA. Characterization of alien aquatic flora of Kashmir Himalaya: implications for invasion management. Trop Ecol. $2014 ; 55(2): 143-57$.

74. Shah M, Ali M, Al-Hemaid F, Reshi ZA. Delimiting invasive Myriophyllum aquaticum in Kashmir Himalaya using a molecular phylogenetic approach. Genet Mol Res. 2014;13(3):7564-70.

75. Wani GA, Shah MA, Reshi ZA, Dar MA. Polyploidy determines the stage of invasion: clues from Kashmir Himalayan aquatic flora. Acta Physiol Plant. 2018;40(3):58

76. Klimešová J, de Bello F, Herben TJ. Searching for the relevance of clonal and bud bank traits across floras and communities. Folia Geobo. 2011;46(23):109-15.

77. Wild J, Kaplan Z, Danihelka J, Petřík P, Chytrý M, Novotný P, et al. Plant distribution data for the Czech Republic integrated in the Pladias database. 2019;91:1-24.

78. R Core Team. A language and environment for statistical computing. R Foundation for Statistical Computing [Internet]. Vienna, Austria; 2016.2014.

79. Liu J, Dong M, Miao SL, Li ZY, Song MH, Wang RQ. Invasive alien plants in China: role of clonality and geographical origin. Biol Invasions 2006;8(7):146170.

80. Reichard SH, Hamilton CW. Predicting invasions of woody plants introduced into North America: Predicción de Invasiones de Plantas Leñosas Introducidas a Norteamérica. Conserv Biol.1997;11(1):193-203

81. Pyšek P, Sádlo J, Mandák B. Catalogue of alien plants of the Czech Republic. Preslia. 2002;74(2):97-186.

82. Maurer DA, Zedler JB. Differential invasion of a wetland grass explained by tests of nutrients and light availability on establishment and clonal growth. Oecologia 2002;131(2):279-88.

83. Shah MA, Callaway RM, Shah T, Houseman GR, Pal RW, Xiao S, et al. Conyza canadensis suppresses plant diversity in its nonnative ranges but not at home: a transcontinental comparison. New Phytol. 2014;202(4):1286-96.

84. Pyšek P, Richardson DM. Invasive species, environmental change and management, and health. Annu Rev Environ Resour. 2010;35.

85. Liu F-H, Yu F-H, Liu W-S, Krüsi BO, Cai X-H, Schneller JJ, et al. Large clones on cliff faces: expanding by rhizomes through crevices. Ann Bot. 2007;100(1):51-4.

86. Aguilera AG, Alpert P, Dukes JS, Harrington R. Impacts of the invasive plant Fallopia japonica (Houtt.) on plant communities and ecosystem processes. Biol Invasions. 2010;12(5):1243-52.

87. Roiloa SR, Rodríguez-Echeverría S, de la Pena E, Freitas H. Physiological integration increases the survival and growth of the clonal invader Carpobrotus edulis. Biol Invasions. 2010;12(6):1815-23.

88. Roiloa SR, Rodriguez-Echeverria S, Lopez-Otero A, Retuerto R, Freitas H. Adaptive plasticity to heterogeneous environments increases capacity for division of labor in the clonal invader Carpobrotus edulis (Aizoaceae). Am J Bot. 2014;101(8):1301-8.

89. Chittka L, Schürkens S. Successful invasion of a floral market. Nature. 2001;411(6838):653-.

90. Minghua S, Ming D. Importance of Clonal Plants in Community. Sheng Tai Xue Bao. 2002;22(11):1960-7.

91. Hutchings M, de Kroon H. Foraging in plants: the role of morphological plasticity in resource acquisition. Adv Ecol Res. 1994. p. 159-238.

92. Ming DJABS. Clonal growth in plants in relation to resource heterogeneity: Foraging behavior. Acta Bot Sin. 1996;38(10):828-35.

93. Song M, Dong M, Jiang G. Importance of clonal plants and plant species diversity in the Northeast China Transect. Ecol Res. 2002;17(6):705-16.

94. Cook RJPb, organisms eoc. Growth and development in clonal plant populations. Population biology and evolution of clonal organisms.1985:259-96.

95. Ming DJCJoPE. Plant clonal growth in heterogeneous habitats: Risk-spreading. Chin J Plant Ecol. 1996;20(6):543.

96. Peltzer DAJAJoB. Does clonal integration improve competitive ability? A test using aspen (Populus tremuloides [Salicaceae]) invasion into prairie. Am $J$ Bot. 2002;89(3):494-9.

97. Pyšek P, Richardson DM. Traits associated with invasiveness in alien plants: where do we stand? Biol Invasions. 2008;97-125.

98. Husband BC, Ozimec B, Martin SL, Pollock L. Mating consequences of polyploid evolution in flowering plants: current trends and insights from synthetic polyploids. Int J Plant Sci. 2008;169(1):195-206.

99. Dar MA, Wani GA, Reshi ZA, Al-Qarawi AA, Abd Allah E, Shah MA. Stage-specific ploidy levelvariations in invasive species in comparison to rare endemics in Kashmir Himalaya. Flora. 2020;262:151525.

100. Stebbins GLJ. Polyploidy, hybridization, and the invasion of new habitats. Missouri Bot Gard. 1985:824-32.

Page 9/16 
101. Levin DA. Polyploidy and novelty in flowering plants. Am Nat.1983;122(1):1-25.

102. Te Beest M, Le Roux JJ, Richardson DM, Brysting AK, Suda J, Kubešová M, et al. The more the better? The role of polyploidy in facilitating plant invasions. Ann Bot. 2012;109(1):19-45.

103. Rosche C, Durka W, Hensen I, Mráz P, Hartmann M, Müller-Schärer H, et al. The population genetics of the fundamental cytotype-shift in invasive Centaurea stoebe sl: genetic diversity, genetic differentiation and small-scale genetic structure differ between cytotypes but not between ranges. Biol Invasions. 2016;18(7):1895-910.

104. Rosche C, Hensen I, Mraz P, Durka W, Hartmann M, Lachmuth S. Invasion success in polyploids: the role of inbreeding in the contrasting colonization abilities of diploid versus tetraploid populations of Centaurea stoebe sl. J Ecol. 2017;105(2):425-35.

105. Nagy DU, Stranczinger S, Godi A, Weisz A, Rosche C, Suda J, et al. Does higher ploidy level increase the risk of invasion? J Plant Ecol. $2018 ; 11(2): 317-27$.

106. Latzel V, Klimešová J. Transgenerational plasticity in clonal plants. Evol Ecol. 2010;24(6):1537-43.

107. Cornelissen JH, Song Y-B, Yu F-H, Dong M. Plant traits and ecosystem effects of clonality: a new research agenda. Ann Bot. 2014;114(2):369-76.

108. Sand-Jensen K, Mebus JR. Fine-scale patterns of water velocity within macrophyte patches in streams. Oikos. 1996:169-80.

109. Ganie AH, Reshi Z, Wafai B, editors. Multiple reproductive strategies contribute to invasiveness of Potamogeton Crispus L.(Potamogetonaceae) in freshwater ecosystems of Kashmir Himalaya, India. Proceedings of Taal 2007: The 12th World Lake Conference; 2007.

110. Gray AJ. Biological Sciences. Do invading species have definable genedc characteristics? Philosophical Transactions of the Royal Society of London. B, Biological Sciences. 1986;314(1167):655-74.

111. Daehler CCJARoE, Evolution, Systematics. Performance comparisons of co-occurring native and alien invasive plants: implications for conservation and restoration. Annu Rev Ecol Evol Syst. 2003;34(1):183-211.

112. Richards CL, Bossdorf O, Muth NZ, Gurevitch J, Pigliucci M. Jack of all trades, master of some? On the role of phenotypic plasticity in plant invasions. Ecol Lett. 2006;9(8):981-93.

113. Richardson DM, Pyšek P. Plant invasions: merging the concepts of species invasiveness and community invasibility. Prog Phys Geogr. $2006 ; 30(3): 409-31$.

114. Funk JL. Differences in plasticity between invasive and native plants from a low resource environment. J Ecol. 2008;96(6):1162-73.

115. Pyšek P. Clonality and plant invasions: can a trait make a difference. The ecology and evolution of clonal plants. 1997:405-27.

116. Eckert CG. The loss of sex in clonal plants. Ecology and evolutionary biology of clonal plants: Springer; 2002; 279-98.

117. Eckert CG, Samis KE, Dart S. Reproductive assurance and the evolution of uniparental reproduction in flowering plants. In:Ecology and Evolution of Flowers(eds Harder LD, BarrettSCH), 2006;183:203.

118. Husband BC, Barrett SCH. Colonization history and population genetic structure of Eichhornia paniculata in Jamaica. Plant Ecol. 1991;66(2):287-96.

119. Kliber A, Eckert CG. interaction between fournder effect and selection during biological invasion in an aquatic plant. Evolution 2005;59(9):1900-13.

120. Ally D, Ritland K, Otto SP. Aging in a long-lived clonal tree. PLoS Biol. 2010;8(8):e1000454.

121. Bobiwash K, Schultz ST, Schoen DJJH. Somatic deleterious mutation rate in a woody plant: estimation from phenotypic data. Heredity. 2013;111(4):33844.

122. Barrett SC, Harder LD. The ecology of mating and its evolutionary consequences in seed plants. Annu Rev Ecol Evol Syst. 2017;6;48

123. Eckert CG, Dorken ME, Barrett SC. Ecological and evolutionary consequences of sexual and clonal reproduction in aquatic plants. Aquat Bot. 2016;135:4661.

124. Li L, Barrett SC, Song Z, Chen J. Sex-specific plasticity of reproductive allocation in response to water depth in a clonal, dioecious macrophyte. Am J bot. 2019;106(1):42- 50.

125. Zhang L-M, Alpert P, Si C, Yu F-H. Interactive effects of fragment size, nutrients, and interspecific competition on growth of the floating, clonal plant Salvinia natans. Aquat Bot. 2019;153:81-7.

\section{Tables}

Table 1: Collection sites spread across lakes, wetlands, rivers and streams with their coordinates. 


\begin{tabular}{|llll|}
\hline Waterbody & Latitude & Longitude & Altitude \\
\hline Ahansar lake & 34.228889 & 74.661389 & 1583 \\
\hline Anchar lake & 34.572778 & 74.791667 & 1584 \\
\hline Dal lake & 34.131944 & 74.855833 & 1584 \\
\hline Manasbal lake & 34.247778 & 74.668611 & 1583 \\
\hline Nilnag lake & 33.856111 & 74.693333 & 2180 \\
\hline Narangbagh lake & 34.980278 & 74.855278 & 1587 \\
\hline Waksar lake & 34.218333 & 74.661111 & 1590 \\
\hline Wular lake & 34.335556 & 74.548333 & 1580 \\
\hline Hokersar wetland & 34.100556 & 74.718889 & 1584 \\
\hline Kranchu wetland & 33.996944 & 74.938611 & 1588 \\
\hline Malangpora wetland & 33.899444 & 74.981944 & 1600 \\
\hline Shallabugh wetland & 34.153333 & 74.737222 & 1580 \\
\hline Tulmula wetland & 34.211389 & 74.730833 & 1610 \\
\hline Jehlum river & 33.200556 & 74.600556 & $* *$ \\
\hline Sindh river & 34.184167 & 74.667222 & $* *$ \\
\hline Achabal & 34.717222 & 75.217222 & 1662 \\
\hline Bal-Kol (Tangmarg) & 34.050556 & 75.417222 & 2010 \\
\hline Stream of Sundoo & 34.683889 & 75.183889 & 1661 \\
\hline Nambal rivulet & 34.667500 & 75.167222 & 1660 \\
\hline Nagrad stream & 34.684167 & 75.183889 & 1661 \\
\hline Aarpath rivulet & 34.685166 & 75.167222 & 1660 \\
\hline Spring stream & 34.667500 & 75.167222 & 1661 \\
\hline Shalimar & 34.834167 & 74.500556 & 1583 \\
\hline Ganderbal & 34.134167 & 74.450556 & 1572 \\
\hline
\end{tabular}

Note: ** represents rivers that traverse along large tracts of landscape.

Table 2: Analysis of the degree of invasiveness and clonality of 102 invasive alien plants species in aquatic habitats in Kashmir Himalaya.

\begin{tabular}{|c|c|c|c|c|c|c|c|c|c|c|c|c|c|}
\hline Invasiveness & Total & Clonal & Clonal o & gans & & & & & & & & & \\
\hline & & $\begin{array}{l}\text { Total } \\
\text { No. }\end{array}$ & Rhizome & Stolon & Tillers & Tubers & Turions & Runner & Buds & Corms & Ramets & Pleiocorm & Fragments \\
\hline Stage II & 15 & 12 & 8 & 1 & 0 & 1 & 3 & 4 & 1 & 0 & 1 & 0 & 0 \\
\hline Stage III & 28 & 24 & 13 & 6 & 0 & 2 & 5 & 9 & 1 & 1 & 0 & 2 & 0 \\
\hline Stage IVA & 08 & 07 & 4 & 0 & 1 & 2 & 1 & 1 & 0 & 0 & 0 & 0 & 0 \\
\hline Stage IVB & 17 & 15 & 9 & 2 & 0 & 0 & 3 & 7 & 2 & 0 & 0 & 0 & 0 \\
\hline Stage V & 34 & 31 & 18 & 1 & 0 & 5 & 9 & 12 & 4 & 0 & 1 & 0 & 3 \\
\hline Total & 102 & 89 & 52 & 10 & 1 & 10 & 21 & 33 & 8 & 1 & 1 & 2 & 3 \\
\hline
\end{tabular}

Table 3: Analysis of 102 alien invasive plant species with different life forms in aquatic habitats of Kashmir Himalaya. 


\begin{tabular}{|c|c|c|c|c|c|c|c|c|c|c|c|c|c|}
\hline Life Forms & Total & Clonal & Clonal c & gans & & & & & & & & & \\
\hline & & $\begin{array}{l}\text { Total } \\
\text { No. }\end{array}$ & Rhizome & Stolon & Tillers & Tubers & Turions & Runner & Buds & Corms & Ramets & Pleiocorm & Fragm \\
\hline Hydrophytes & 47 & 46 & 24 & 6 & 0 & 4 & 19 & 17 & 5 & 0 & 0 & 0 & 3 \\
\hline Geophytes & 15 & 14 & 9 & 1 & 0 & 4 & 2 & 4 & 0 & 0 & 1 & 0 & 0 \\
\hline Therophytes & 14 & 7 & 2 & 1 & 1 & 2 & 0 & 1 & 1 & 1 & 1 & 1 & 0 \\
\hline Hemikryptophytes & 26 & 23 & 18 & 2 & 0 & 0 & 0 & 11 & 2 & 0 & 0 & 1 & 0 \\
\hline
\end{tabular}

Table 4: Invasion stages with percentage of clonality.

\begin{tabular}{|llll|}
\hline Invasiveness & Total no. of plants & No. of clonal plants & Percentage of clonality \\
\hline Stage II & 15 & 12 & $80 \%$ \\
\hline Stage III & 28 & 24 & $85.70 \%$ \\
\hline Stage IVA & 8 & 7 & $87.50 \%$ \\
\hline Stage IVB & 17 & 15 & $88.25 \%$ \\
\hline Stage V & 34 & 31 & $91.17 \%$ \\
\hline Total & 102 & 89 & $87.25 \%$ \\
\hline
\end{tabular}

Table 5: Correlation matrix of the clonality and other variables (clonal growth organs).

\begin{tabular}{|c|c|c|c|c|c|c|c|c|c|c|c|c|c|}
\hline & Clonality & Rhizome & Stolon & Tiller & Tubers & Turion & Runner & Buds & Corm & Ramet & Pleiocorm & Fragments & Bulbs \\
\hline Clonality & 1 & & & & & & & & & & & & \\
\hline Rhizome & 0.92 & 1 & & & & & & & & & & & \\
\hline Stolon & 0.45 & 0.73 & 1 & & & & & & & & & & \\
\hline Tiller & -0.63 & -0.63 & -0.42 & 1 & & & & & & & & & \\
\hline Tubers & 0.79 & 0.7 & 0.15 & -0.1 & 1 & & & & & & & & \\
\hline Turion & 0.85 & 0.76 & 0.14 & -0.49 & 0.87 & 1 & & & & & & & \\
\hline Runner & 0.92 & 0.87 & 0.61 & -0.68 & 0.55 & 0.59 & 1 & & & & & & \\
\hline Buds & 0.69 & 0.34 & -0.28 & -0.38 & 0.58 & 0.63 & 0.58 & 1 & & & & & \\
\hline Corm & 0.36 & 0.66 & 0.98 & -0.25 & 0.15 & 0.05 & 0.52 & -0.38 & 1 & & & & \\
\hline Ramet & -0.34 & -0.2 & -0.19 & -0.25 & -0.34 & 0.05 & -0.48 & -0.38 & -0.25 & 1 & & & \\
\hline Pleiocorm & 0.36 & 0.66 & 0.98 & -0.25 & 0.15 & 0.05 & 0.52 & -0.38 & 1 & -0.25 & 1 & & \\
\hline Fragments & 0.95 & 0.84 & 0.3 & -0.38 & 0.95 & 0.9 & 0.78 & 0.69 & 0.25 & -0.38 & 0.25 & 1 & \\
\hline Bulbs & 0.36 & 0.66 & 0.98 & -0.25 & 0.15 & 0.05 & 0.52 & -0.38 & 1 & -0.25 & 1 & 0.25 & 1 \\
\hline
\end{tabular}

Table 6. Eigen values for the relation of clonal growth organs and stages of invasion 


\begin{tabular}{|llll|}
\hline Parameters & PC1 & PC2 & PC3 \\
\hline Clonality & 0.37 & -0.051 & 0.056 \\
\hline Rhizome & 0.383 & -0.010 & -0.011 \\
\hline Stolon & 0.129 & -0.437 & -0.116 \\
\hline Tiller & -0.254 & 0.083 & 0.682 \\
\hline Tubers & 0.276 & 0.141 & 0.572 \\
\hline Turion & 0.379 & 0.058 & 0.060 \\
\hline Runner & 0.370 & -0.051 & -0.114 \\
\hline Buds & 0.330 & 0.194 & -0.146 \\
\hline Corm & 0.098 & -0.445 & 0.128 \\
\hline Ramet & 0.182 & 0.282 & -0.195 \\
\hline Pleiocorm & 0.098 & -0.445 & 0.128 \\
\hline Fragments & 0.311 & 0.242 & 0.252 \\
\hline Bulbs & 0.098 & -0.445 & 0.128 \\
\hline Standard deviation & 2.606 & 2.130 & 1.058 \\
\hline Proportion of Variance & 0.522 & 0.349 & 0.086 \\
\hline Cumulative Proportion & 0.522 & 0.871 & 0.958 \\
\hline
\end{tabular}

Table 7: Eigen values of the first three principal components.

\begin{tabular}{|llll|}
\hline Parameters & PC1 & PC2 & PC3 \\
\hline Clonality & -0.337 & -0.088 & 0.067 \\
\hline Rhizome & -0.317 & -0.189 & -0.154 \\
\hline Stolon & -0.232 & -0.062 & 0.237 \\
\hline Tiller & 0.236 & -0.082 & 0.547 \\
\hline Tubers & -0.141 & 0.536 & 0.161 \\
\hline Turion & -0.314 & -0.094 & 0.274 \\
\hline Runner & -0.322 & -0.200 & -0.040 \\
\hline Buds & -0.297 & -0.190 & 0.289 \\
\hline Corm & 0.236 & -0.028 & 0.547 \\
\hline Ramet & 0.254 & 0.397 & 0.100 \\
\hline Pleiocorm & 0.2196 & -0.457 & 0.103 \\
\hline Fragments & -0.311 & 0.040 & 0.311 \\
\hline Bulbs & 0.2196 & -0.457 & 0.103 \\
\hline Standard deviation & 2.9213 & 1.651 & 1.3192 \\
\hline Proportion of Variance & 0.6564 & 0.2097 & 0.133 \\
\hline Cumulative Proportion & 0.6564 & 0.8661 & 1 \\
\hline
\end{tabular}

Table 8: Analyses of geographic origins of 102 invasive alien plant species in Kashmir Himalaya. 


\begin{tabular}{|llllll|}
\hline Invasiveness & North America & South America & Europe & Africa & Asia \\
\hline Stage II & 5 & 0 & 9 & 0 & 1 \\
\hline Stage III & 6 & 3 & 19 & 1 & 3 \\
\hline Stage IVA & 1 & 0 & 6 & 1 & 0 \\
\hline Stage IVB & 1 & 1 & 13 & 0 & 2 \\
\hline Stage V & 3 & 1 & 30 & 0 & 2 \\
\hline Total & 16 & 5 & 77 & 2 & 8 \\
\hline
\end{tabular}

\section{Figures}

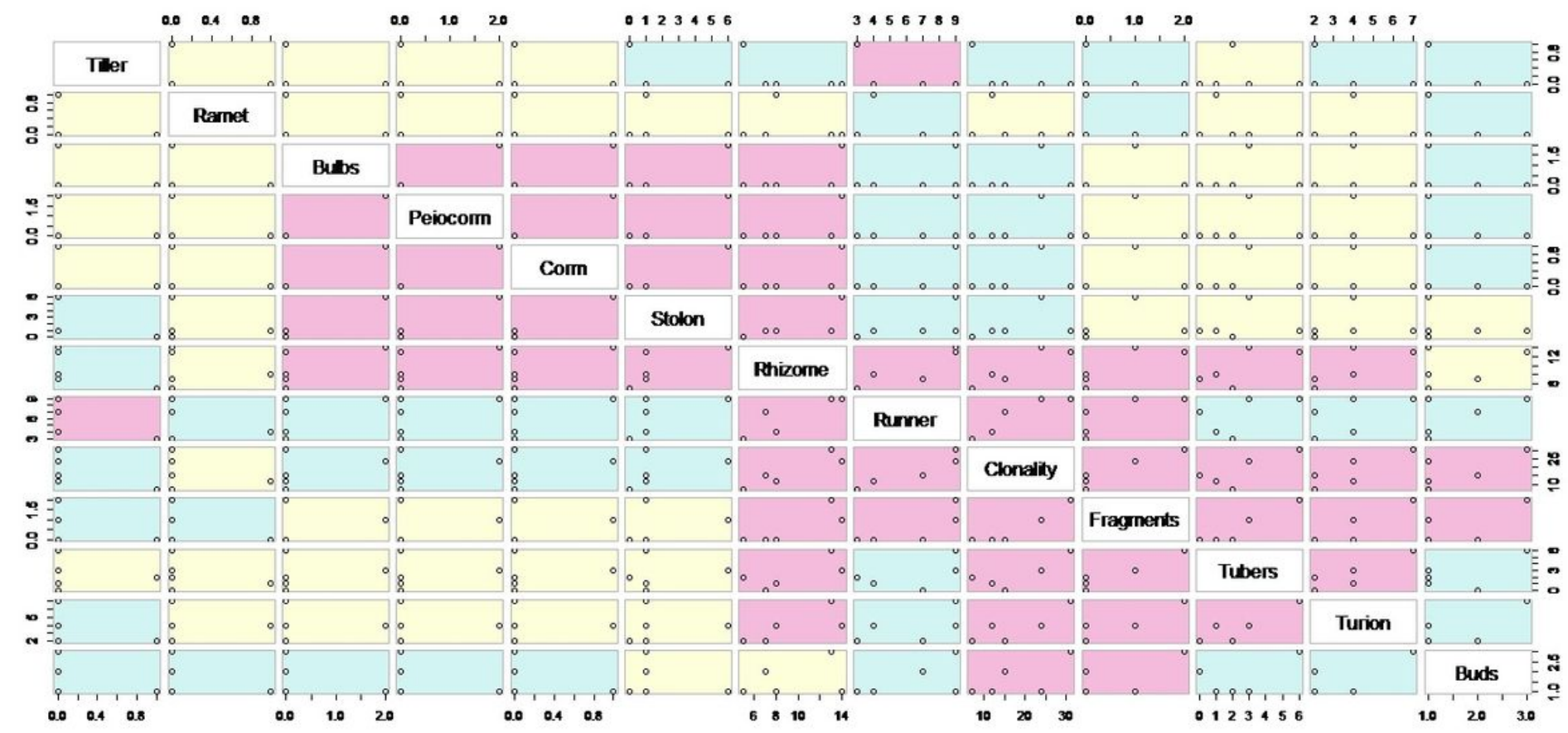

\section{Figure 1}

Scatter matrix showing the strength of correlation between clonality and different variables (clonal growth organs). Pink, blue and white boxes respectively indicate strong, moderate and weak correlations. 


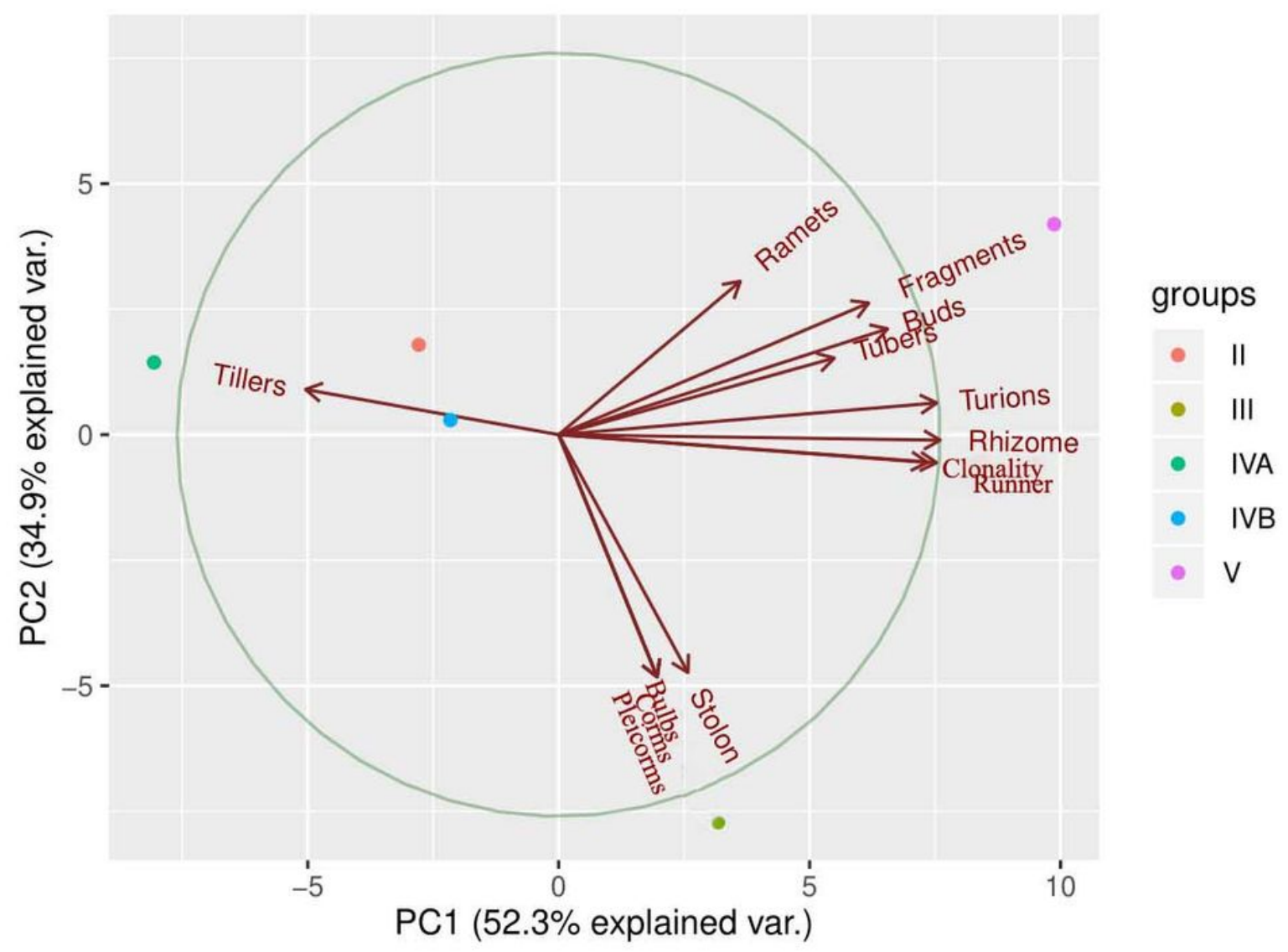

Figure 2

Loadings of the 12 variables (CGO's) and scores of the invasion stages (II-V) on the plane defined by principal components 1 and 2.

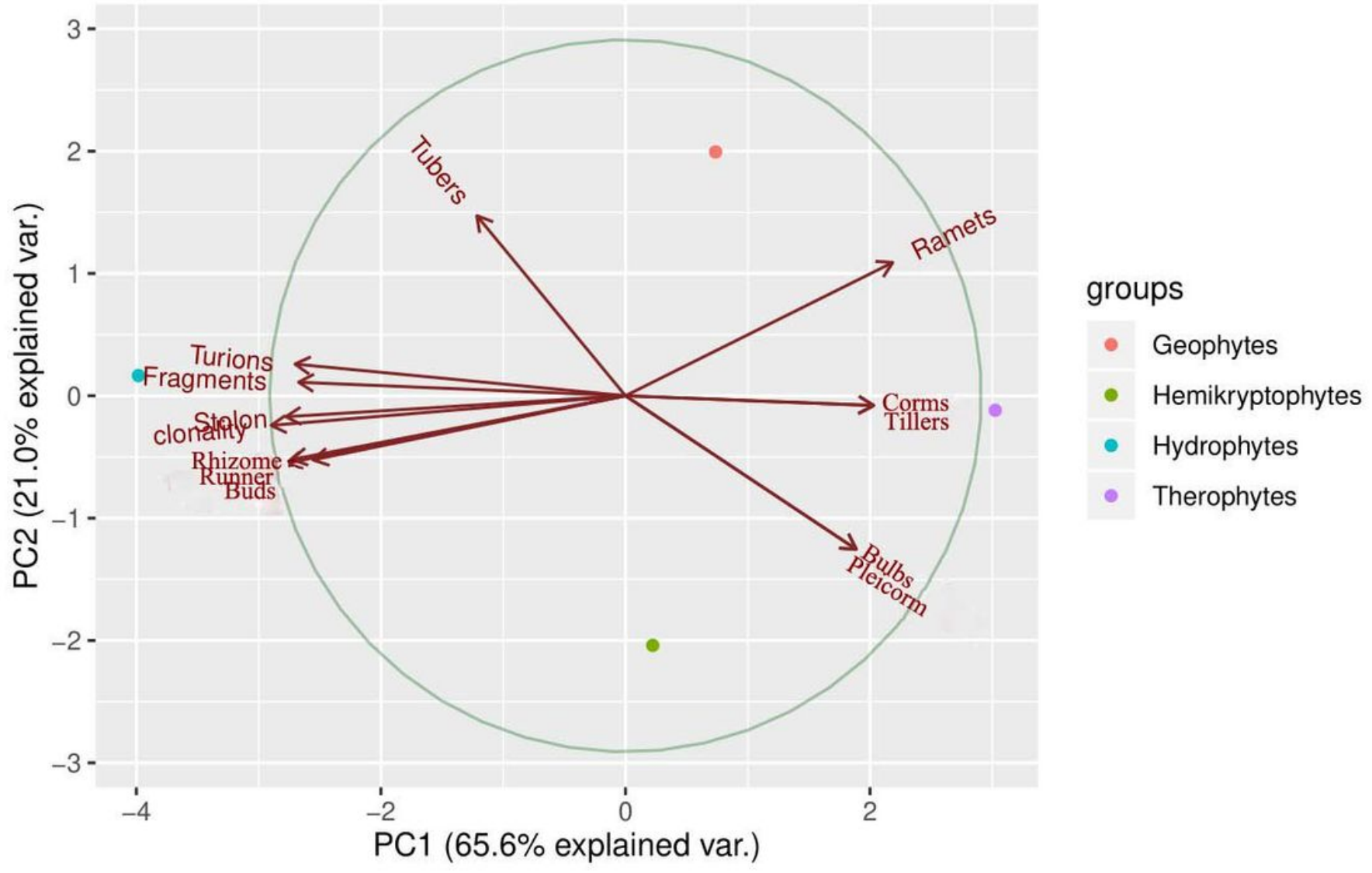


Loadings of the 12 clonal growth organ variables and scores of the four different life forms (Hydrophytes, geophytes, therophytes and hemicryptophytes) on the plane defined by principal components.

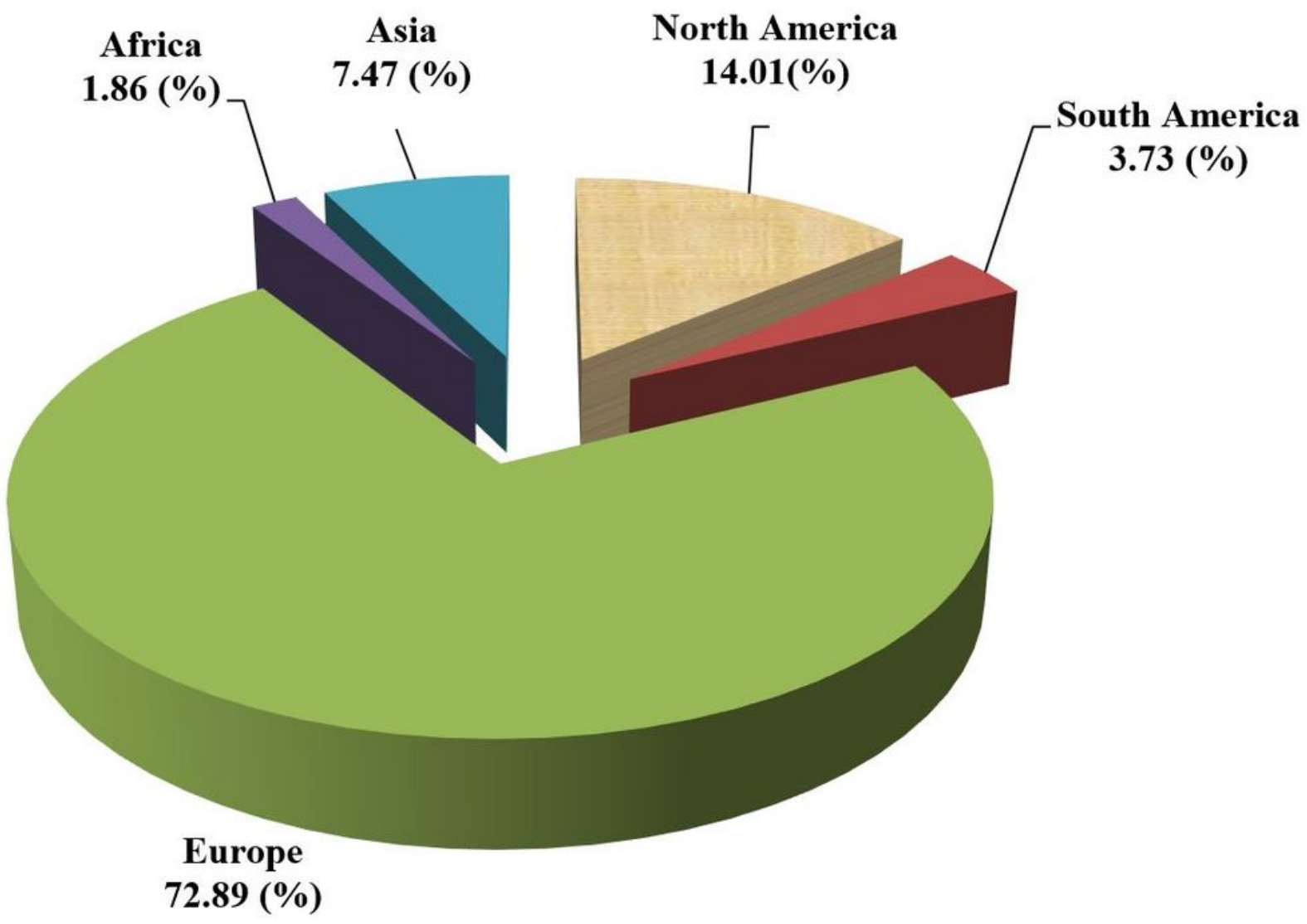

Figure 4

Contribution of various source regions to the Kashmir Himalayan aquatic alien flora. Figures in parentheses represent the percentage of species native to each continental region.

\section{Supplementary Files}

This is a list of supplementary files associated with this preprint. Click to download.

- RevAppendix.docx 